\title{
Prospective Mathematics Teachers' Pedagogical Content Knowledge in Teaching Mathematics Using Flipped Classroom Strategy
}

\author{
Hongki Julie ${ }^{1, *}$ \\ ${ }^{1}$ Mathematics Education Department, Sanata Dharma University, Indonesia \\ *Corresponding author.Email: hongkijulie@yahoo.co.id
}

\begin{abstract}
The purposes of this study are to describe (1) how the learning trajectory of students taking Micro Teaching courses in class D for the 2020/2021 academic year is so that students can practice the Flipped Learning model, and (2) how the Pedagogical Content Knowledge (PCK) of students who take the Micro Teaching course in practicing the Flipped Learning model in every phase is. The subjects of this study were 18 students. This study employed design research. Data collection methods used in this study were observation and documentation. The instrument used in this study was an observation sheet containing PCK components that need to be observed when each student is doing the flipped learning process in every phase. The results of the observation of student practice were as follow: (1) more than $70 \%$ of students only use one representation in conveying messages at the pre-phase stage, giving greetings, and asking students how their condition is; (2) there are two video streams made by students, and (3) there are two learning paths made by students in the synchronous phase.
\end{abstract}

Keywords: Pedagogical Content Knowledge, Flipped Classroom, Bloom's Taxonomy.

\section{INTRODUCTION}

The learning process that must be carried out by schools starting from PAUD to SMA levels during the Covid-19 emergency response period in Indonesia based on the Policy of the Indonesian Ministry of Education and Culture is a distance learning process [1]. Learning that occurs when teachers and students interact at different times and/or places and use a variety of different teaching facilities and materials is referred to as distance learning [2]. One of the impacts of the policy of the Ministry of Education and Culture of Indonesia is that the learning process so far has been carried out in the form of face-toface meetings and must be held by teachers online and teachers are not accustomed to conducting online learning processes. This policy also has an impact on the process of preparing prospective teachers in the teacher training faculty. The teacher training faculty must prepare their graduates to be competent in conducting online learning processes. One of the courses in the teacher training faculty that are directly related to helping prospective teachers to achieve these competencies is the Micro Teaching course. Therefore, one of the practices that must be developed in the course is the practice of online learning.

One of the online learning models is the Flipped Learning model. The Flipped Classroom learning model is a blended learning model that combines synchronous learning with asynchronous independent learning [3]. Flipped Classroom is an instructional strategy that can provide educators with a way of minimizing the amount of direct instruction in their teaching practice while maximizing one-to-one interaction [4].

Flipped classroom is a new pedagogical method, which employs asynchronous video lectures and practice problems as homework, and active, group - based problem-solving activities in the classroom [5]. There are four phases in Flipped Classroom learning model [6], namely: (a) pre-phase, (b) self-learning phase, (c) synchronous, online face - to - face phase, and (d) transfer phases [6]. In the pre-phase, the teacher conveys related technical and some information about the learning that will be implemented. In the self-learning phase, students learn independently, either through learning videos or written materials. In the synchronous phase, the teaching 
- learning process requires the presence of students and teachers at the same time. This learning is mentored by educators in real time and in an interactive way. In the transfer phase, students must deepen learning outcomes, where students can apply knowledge and skills to other contexts. This can be achieved with small projects and students must work collaboratively. When viewed from the phases above, broadly speaking, flipped classroom

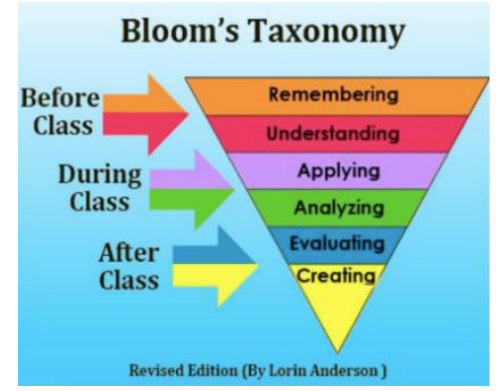

Figure 1 The relationship between the phases in Flipped Classroom learning model and Bloom's

Taxonomy (Accessed on October 11, 2021 from https://www.usd.ac.id/center/ppip/2020/05/04/concept -dasar- method-flipped-classroom/.

learning model is divided into three main activities, namely, (1) before class starts (pre-class), (2) when class starts (in-class), and (3) after the class ends (out of class). Before the class begins, students have studied the materials to be discussed. At this stage, the abilities that are expected to be possessed by students are remembering and understanding the materials. Thus, when the class starts, students can apply and analyze materials through various interactive activities in the classroom, which are then followed by evaluating and working on certain project-based tasks as activities after the class ends. The relationship between the phases in flipped classroom learning model and Bloom's Taxonomy can be described as follows.

Pedagogical Content Knowledge (PCK) is defined as teacher knowledge about (1) how to represent and formulate learning materials so that they are easily understood by students, (2) what makes learning materials easy or difficult for students to understand, and (3) how to re-arrange the knowledge that students already have about the learning materials that they are learning [7]. The term PCK proposed in [7] describes the mixture of content and pedagogical aspects which is the domain of the teacher. According to them, PCK is the teacher's knowledge of how a particular topic, problem, or issue is organized, represented, and adapted to students' diverse interests and abilities, and presented in learning [8]. The elements in PCK can be categorized into three categories, namely (a) "clear" PCK category where pedagogical and content elements are completely intertwined, (b) category of content knowledge in the context of pedagogy, and (c) category of pedagogical knowledge in the context of content [8]. Knowledge that is included into the "clear"
PCK category are knowledge of teaching strategies, how students think, alternative models and representations, learning resources and curriculum. Knowledge that is included into the category of content knowledge in the context of pedagogy is knowledge about deconstructing existing knowledge in content into its key components, mathematical structures and their relationships, and Profound Understanding of Fundamental Mathematics (PUFM). Knowledge that included into the category of pedagogical knowledge in the context of content covers situations where knowledge about teaching is applied in a particular area of learning materials, knowledge to obtain and cultivate student learning focus, and knowledge of classroom management techniques [8]. The research questions of this study are as follow: (1) how is the learning trajectory of students taking Micro Teaching course so that students can practice the Flipped Learning model? and (2) how is the PCK of students taking Micro Teaching course in practicing Flipped Learning model in every phase?

\section{METHODS}

In this study, the researcher used the Cobb and Gravemeijer design research model which consisted of three stages [9]. The researcher used this type of research because in this study, the researcher aimed to (1) build a learning trajectory for students taking Micro Teaching course to practice Flipped Learning model, and (2) find out how the PCK of students taking Micro Teaching course in practising the Flipped Learning model in every phase. The subjects of the study were 18 students of the Mathematics Education Study Program who took Micro Teaching course in class D from the 2020/2021 academic year. The method used in collecting data was observation on the practice carried out by each student. To assist the observation process, the researcher employed PCK instruments in the pre-phase, the self-learning phase, the synchronous phase, and the transfer phase. The data analysis technique used in this study was qualitative data analysis technique according to Miles and Huberman which consists of three stages, namely: reducing data, presenting data, and making conclusions [10].

\section{RESULTS AND DISSCUSSION}

\subsection{Description of the Learning Process}

\subsubsection{Pre-phase}

The lecturer explained to students via chat on WA about how students would experience the learning process starting from the pre-phase to the transfer phase.

\subsubsection{Self-learning phase}

One day before the face-to-face meeting, students were given the materials to study in the form of a power 
point file containing the following: (a) the Ministry of Education and Culture's policy regarding the learning process during the COVID-19 emergency response period, (b) the four things that teachers must pay attention to in managing the learning process during the COVID19 emergency response period, which are based on the Ministry of Education and Culture policies, (c) the definition of distance learning according to [2], and the notion of online learning according to Means, B., Bakia, M., and Murphy, R. (2014) [11], (d) the two online learning models, namely the asynchronous online learning model and the synchronous online learning model, (e) the definition of asynchronous online learning model according to [12], (f) the definition of synchronous online learning model according to [12], (g) the definition of the Flipped Learning model according to [3], [4], and [5] (h) the phases of Flipped Learning model according to [6], (i) the relationship between the learning process in Flipped Learning model and Bloom's Taxonomy, (j) the things that every student must do at every phase in the Flipped Learning model, (k) the agenda for learning activities which is to carry out teaching practices using the Flipped Learning model.

\subsubsection{Synchronous phase}

The Synchronous Phase were held on April 28, 2021 via Zoom platform. The process that occured in the faceto-face meeting were as follows: (a) one of the students was asked to open with a prayer; (b) the lecturer explained the learning objectives and the learning process that would be carried out face-to-face on that day; (c) students were asked about the difference between distance learning and online learning. Three students were asked to explain the answers to the questions. The lecturer summarized the answers of the three students about the difference between distance learning and online learning; (d) students were asked about the difference between asynchronous and synchronous online learning models. Three students were asked to explain the answers to the questions. The lecturer summarized the answers of the three students about the difference between asynchronous and synchronous online learning models; (e) students were asked about the definition of Flipped Learning model. Three students were asked to explain the answer to the question. The lecturer summarized the students opinions about what Flipped Learning is; (f) students were asked whether the learning model used by the lecturer to introduce Flipped Learning model was the Flipped Learning model. Three students were asked to explain the answer to the question; (g) the lecturer reviewed the definition of Flipped Learning model according to [3], and [5]; (h) students were asked about what teachers and students did in the pre-phase stage of the Flipped Learning phases according to [6]. Three students were asked to explain the answer to the question. The lecturer summarized the students' opinions about what teachers and students did in the pre-phase stage of the Flipped Learning phases; (h) students were asked about what teachers and students did in the independent learning phase. Three students were asked to explain the answer to the question. The lecturer reviewed the students' opinions about what students and teachers did in the independent learning phase; (i) students were asked what the teacher and students did in the synchronous phase. Three students were asked to explain the answer to the question.

The lecturer reviewed the students' answers about what students and teachers did in the transfer phase; $(\mathrm{k})$ the lecturer explained the relationship between the phases in Flipped Learning model and Bloom's Taxonomy; (1) the lecturer explained the tasks that must be done by each student in each phase of Flipped Learning; (m) the lecturer explained the implementation schedule for each phase in Flipped Learning; (n) the lecturer explained the technical implementation of the learning process for each learning phase in Flipped Learning; (o) the lecturer concluded the results of the learning process in the meeting that day; and (p) the lecturer closed the lesson.

\subsubsection{Transfer Phase}

The following are the steps taken by students in the transfer phase, namely: (a) students made lesson plans for teaching Mathematics at the high school level using the Flipped Learning model; (b) students carried out the learning process using the Flipped Learning model with the following schedule: 1) pre-phase on 28 April - 4 May 2021; 2) self-learning phase: a) uploading the learning video and PPT that students need to read as well as lesson plans on 5 - 11 May 2021, and b) students who act as students independently learned the video that has been uploaded by teachers on 12 - May 16, 2021; 3) synchronous learning phase and transfer phase on $17-31$ May 2021. Each practitioner got a maximum time of 35 minutes; c) reflection on June 2, 2021.

\subsection{Pre-Phase Analysis}

The questions in the pre-phase PCK instrument are as follows: (1) what media are used by students to do the pre-phase; (2) what form of explanation representation is made by students; (3) how is the representation of greetings made by students; (4) do students ask students how they are doing; (5) how do students explain the prephase; (6) how do students explain the self-learning phase; (7) how do students explain the synchronous phase; and (8) how do students explain the transfer phase.

The results of the pre-phase analysis conducted by the students are as follow: (1) the number of learning media used by students: (a) three media, namely WA text, WA voice messages, and text on file used by one student; (b) three media, namely WA text, WA voice messages, and pictures used by two students; (c) two media, namely WA text and WA voice messages used by one student; (d) two media, namely WA text and text on file used by one 
student; (e) one medium, namely WA text used by 11 students; (f) one medium, namely WA voice messages used by two students; (2) the number of students greeting and asking how they are: (a) thirteen students greeted and asked how they were doing; and (b) five students greeted but did not ask how they were doing; and (3) the phases described by students: (a) eight students explained what students needed to do in each phase of the four phases of Flipped Learning model in the form of a narrative description; (b) three students explained what students needed to do in each phase for the three phases, namely the pre-phase, the self-learning phase, and the synchronous phase of the four phases of Flipped Learning model in the form of a narrative description; (c) seven students explained what students needed to do in each phase for two phases, namely the pre-phase and the selflearning phase of the four phases of Flipped Learning model in the form of a narrative description.

\subsection{Self-Learning Phase Analysis}

There are three questions in the self-learning phase instrument, namely: (1) how the flow of the learning video is made by students; (2) what is the level of questions given by students in the learning video; and (3) what is the level of practice questions, if any, given by students to be done by students after they watch the learning video. From the results of the analysis of the learning video made by students, in general it was found that there were two video streams, namely: (1) the first stream is to explain the definition and/or procedure, explain examples and not examples of the definition and/or procedure, explain the steps to solve the application problem of the definition and/or procedure. There were 13 students who made the video following this path (2) the second stream is to explain the process of solving the problem, explain the relationship between the problem and the definition and/or procedure that could be built from the problem-solving process, and explain the steps to solve the application problem of the definition and/or procedure. There were five students who made the video following this stream, namely $18-63,18-35,18-$ $66,18-48$, and 18-46.

From the data analysis, it can be concluded that (1) for students who make the video with first stream, the level of questions made by students in the video is at levels $\mathrm{C} 1$, $\mathrm{C} 2, \mathrm{C} 3$, and $\mathrm{C} 4$ and the level of practice questions made, if any, is at level C3, (2) for students who make the video with second flow, then the level of questions made by students in the video is at levels $\mathrm{C} 3, \mathrm{C} 4$, and $\mathrm{C} 5$, and the level of practice questions made, if any, is at level C3 and $\mathrm{C} 5$, and (3) for students who made the video with the second stream, there was a tendency for the practice questions made by them to be at a higher level than the students who made the video with the first stream.

\subsection{Synchronous Phase Analysis}

There are three questions in the synchronous phase instrument, namely: (1) how the flow of learning in the synchronous phase is; (2) what the level of quiz questions is made by students in synchronous learning; and (3) what is the level of questions given by students for students to discuss in the synchronous phase. From the results of observations during practice in the synchronous phase, the researcher found that there were two learning paths carried out by students, namely: (1) the teacher greeted, asked news of students, explained learning objectives, gave quizzes, discussed quiz answers, asked students difficulties in understanding the learning video made by the teacher, discussed practice questions given to students in the independent learning phase with the following process: (a) asking students to explain the answers to practice questions that have been made by the students, and (b) discussing the students' answers, made conclusions, made reflections on the process experienced from the pre-phase to the synchronous phase, gave questions or projects that need to be completed by the students in the transfer phase. There are three out of 18 students who teach mathematics following this first path in the synchronous phase; (2) the teacher greeted, asked how things were, explained learning objectives, gave quizzes, discussed quiz answers, asked students' difficulties in understanding the learning video made by the teacher, discussed practice questions, if any, given to students in the self-learning phase with the following process: (a) asking students to explain the answers to practice questions that have been made by students, and (b) discussing the answers of these students, gave questions to be discussed in groups, asked students to explain answers to discussion questions that have been made by students in groups, discussed group answers presented by the students, drew conclusions, reflected on the process experienced from the pre-phase to the synchronous phase, provided questions or projects that students needed to complete in the transfer phase. There were 15 out of 18 students who teach mathematics following this second path in the synchronous phase.

The conclusions that could be drawn from the data analysis were as follow: (1) six out of 13 students who made the video with the first stream needed help to develop their ability in making quiz questions, (2) four out of 13 students who made the video with the first stream needed help to develop the ability to boost discussion questions in the synchronous phase, and (3) three out of five students who made the video with the second stream needed help to develop their skills in making quiz questions and boosting discussion questions in the synchronous phase. Therefore, less than fifty percent of students who made the video with the first stream needed help to develop their ability in making quiz questions and boosting discussion questions in the synchronous phase, and more than fifty percent of students who made the video with the second stream needed help to develop skills in creating quiz questions 
and boosting discussion questions in the synchronous phase.

\subsection{Transfer Phase Analysis}

There is one question in the transfer phase instrument, namely: what is the level of questions given by students in the transfer phase? The conclusions that could be drawn from the data analysis are as follow: (1) nine out of 13 students who made the video with the first stream needed helped to develop their ability to make questions in the transfer phase, and (2) three out of five students who made the video with second stream needed to be assisted to develop the ability to make questions in the transfer phase. Thus, the percentage of students who made the video with the first stream that needs help in making questions in the transfer phase is bigger than students who made the video with the second stream.

\section{CONCLUSION}

There are several conclusions that can be drawn from the results of this study, namely: (1) more than $70 \%$ of students only used one representation in conveying messages at the pre-phase stage, greetings, and asking students how they are in the message; (2) not more than $40 \%$ of students explained what students and teachers do in each phase of the Flipped Learning model; (3) there were two video streams made by students. Less than $50 \%$ of students who made the video with the first stream needed help to develop their ability to make quiz questions and discussion questions in the synchronous phase; (4) more than $50 \%$ of students who made the video with the second stream needed help to develop their ability to make quiz questions and discussion questions in the synchronous phase; (5) the level of questions made by students who made the video with second stream is higher than the level of questions made by students who made the video with first stream; (6) the level of practice questions made by students who made the video with second stream is higher than the level of questions made by students who made the video with first stream; (7) there are two learning paths made by students in the synchronous phase. There are three students who use the first path, while fifteen other students use the second path in teaching Mathematics in the synchronous phase; and (8) the percentage of students who made the video with the first stream that needed help in making questions in the transfer phase is bigger than those who made the video with the second stream.

\section{REFERENCES}

[1] Ministry of Education and Culture. Surat Edaran Nomor 2 Tentang Pencegahan dan Penanganan Corona Virus Disease (Covid-19). Jakarta: Ministry of Education and Culture (2020)
[2] J. L. Moore, C. Dickson-Deane, \& K. Galyen, eLearning, online learning, and distance learning environments: Are they the same?. The Internet and Higher Education, 14(2) (2011) 129-135.

[3] PPIP. (2020). Konsep Dasar Metode Flipped Classroom. Accessed on 11 October 2021 from https://www.usd.ac.id/pusat/ppip/2020/05/04/konse p-dasar-metode-flipped-classroom/.

[4] G. B. Johnson, Student perceptions of the flipped classroom (Thesis Master, University of British Columbia, 2013). Accessed on 11 October 2021 from

https://open.library.ubc.ca/soa/cIRcle/collections/u bctheses/24/items/1.0073641.

[5] J. L. Bishop, and M. A. Verleger, The Flipped Classrom: A Survey of the Research. Proceeding of 120 th ASEE Conference and Exposition, Atlanta, 2013, pp. 23 - 26 June 2013.

[6] D. Tolks, B. Romeike, J. Ehlers, S. Kuhn, C. Kleinsorgen, J. Huber, M. Fischer, C. Bohne, I. Hege, The online inverted classroom model (oICM). A blueprint to adapt the inverted classroom to an online learning setting in medical and health education. AMEE, 9 (2020). https://doi.org/10.15694/mep.2020.000113.1.

[7] L. S. Shulman, Those who understand: Knowledge growth in teaching, Educational Researcher, 15(2) (1986) 4- 31.

[8] H. Chick, M. Baker, T. Pham, \& H. Cheng, Aspects of teachers' pedagogical content knowledge for decimals. Proceedings of 30th Conference of the International Group for the Psychology of Mathematics Education, Vol. 2, 2006, pp. 297-304.

[9] J. V. D. Akker, K. Gravemeijer, S. McKenney, and N. Nieveen, Educational Design Research. New York: Taylor and Francis Group, 2006.

[10] M. B. Miles, and A. M. Huberman, Qualitative Data Analysis. London: Sage Publications, 1994.

[11] B. Means, M. Bakia, and R. Murphy, Learning online: What research tells us about whether, when, and how. New York: Routledge, 2014..

[12] P. J. Fadde, \& P. Vu, Blended online learning: Benefits, challenges, and misconceptions. In P. R. Lowenthal, C. S. York, \& J.C. Richardson (Eds.). Online learning: Common misconceptions, benefits, and challenges. Hauppauge, YU. Nova Publishers, 2014, pp. 38- 48 . 